\title{
h-prune affects anaplastic thyroid cancer invasion and metastasis
}

\author{
JUNKO NAMBU $^{1,2}$, TSUYOSHI KOBAYASHI $^{1}$, MASAKAZU HASHIMOTO $^{1}$, HIROTAKA TASHIRO ${ }^{1}$, \\ KEIZO SUGINO ${ }^{2}$, FUMIO SHIMAMOTO ${ }^{3}$, AKIRA KIKUCHI ${ }^{4}$ and HIDEKI OHDAN ${ }^{1}$ \\ ${ }^{1}$ Department of Gastroenterological and Transplant Surgery, Applied Life Sciences, Institute of \\ Biomedical and Health Sciences, Hiroshima University, Hiroshima; ${ }^{2}$ Department of Surgery, Tsuchiya \\ General Hospital, Hiroshima; ${ }^{3}$ Department of Health Science, Faculty of Human Culture and Society, \\ Prefectural University of Hiroshima, Faculty of Human Culture and Society, Hiroshima; ${ }^{4}$ Department of \\ Molecular Biology and Biochemistry, Graduate School of Medicine, Osaka University, Osaka, Japan
}

Received January 9, 2016; Accepted March 16, 2016

DOI: $10.3892 /$ or.2016.4759

\begin{abstract}
Anaplastic thyroid cancer is one of the most aggressive human malignancies and is resistant to multimodal treatments. The expression of h-prune, the human homologue of Drosophila prune, has been reported to be correlated with progression and aggressiveness in various cancers including breast, colorectal and pancreatic cancers. We examined the role of h-prune in anaplastic thyroid cancer cell migration, invasion and metastasis. Immunohistochemical analysis of h-prune was performed with 15 surgically resected specimens of anaplastic thyroid cancers. To investigate cell motility, Boyden chamber, wound healing and Matrigel invasion assays were performed using cells from anaplastic thyroid cancer cell lines. A murine orthotopic thyroid cancer model was used to investigate metastatic ability. In the immunohistochemical analysis, only weak focal or no staining of h-prune was observed in non-tumor tissue. In contrast, diffuse staining of h-prune was observed in anaplastic thyroid cancer and lymph node metastasis samples. Both inhibition of h-prune phosphodiesterase activity with dipyridamole and small interfering RNA for h-prune suppressed $8505 \mathrm{C}$ and KTC-3 cell motility. In addition, treatment with dipyridamole and decreased expression of h-prune suppressed tumor invasion and pulmonary metastasis in a NOD/Shi-scid, IL-2R $\gamma$ null (NOG) mouse orthotopic thyroid cancer model. In conclusion, h-prune is frequently expressed in anaplastic thyroid cancer cells and lymph nodes metastasis, and promotes migration and invasion of anaplastic thyroid cancer cells and metastasis in an anaplastic thyroid cancer model. Thus, h-prune shows promise as a targeting candidate against anaplastic thyroid cancer.
\end{abstract}

Correspondence to: Dr Tsuyoshi Kobayashi, Department of Gastroenterological and Transplant Surgery, Applied Life Sciences, Institute of Biomedical and Health Sciences, Hiroshima University, 1-2-3 Kasumi, Minami-ku, Hiroshima 734-8551, Japan

E-mail: tsukoba@hiroshima-u.ac.jp

Key words: anaplastic thyroid cancer, metastasis, invasion, migration, h-prune

\section{Introduction}

Anaplastic thyroid cancer (ATC) is a very aggressive malignancy with a poor prognosis, with a median survival of approximately 3-5 months following diagnosis. Although ATC accounts for less than 1-3\% of all thyroid cancers, it is responsible for $14-39 \%$ of thyroid cancer-related deaths (1-9). Thus, it is important to clarify the molecular mechanism underlying the highly aggressive nature of ATC. Recently, several clinical trials have tested the efficacy of small molecule tyrosine kinase inhibitors, antiangiogenesis agents, and vascular-disrupting agents; these show promise as additional drugs to combat ATC, in addition to the multimodal therapy, including surgical resection, radiotherapy and chemotherapy, that has long been used (10). However, a standard therapy for ATC remains to be established.

The human (h)-prune protein is a member of the desert hedgehog homolog (DHH) protein superfamily, and it is known to have a cAMP phosphodiesterase (PDE) activity (11). Its overexpression in breast, colorectal and gastric cancers is correlated with depth of invasion and a high degree of lymphnode metastasis (12-14). We previously identified h-prune as a binding protein of a serine/threonine kinase, glycogen synthase kinase-3 (GSK-3) (15). The binding of h-prune to GSK-3 was involved in the regulation of the disassembly of focal adhesions to promote cell migration. $\mathrm{H}$-prune protein expression was correlated with depth of invasion and degree of lymph-node metastasis in colorectal and pancreatic cancers.

Thus, although expression of h-prune is correlated with progression and aggressiveness in various cancers, the role of h-prune in thyroid cancer has not been investigated. In the present study, we investigated whether h-prune affects the ability of invasion and metastasis of anaplastic thyroid cancer cells.

\section{Materials and methods}

Tissue samples and immunohistochemistry. Tissue samples were collected from 15 ATC patients who underwent surgery between 2003 and 2010 at Tsuchiya General Hospital (Hiroshima, Japan). We investigated the expression of 
h-prune by immunohistochemical analysis of ATC tissues, corresponding non-tumor thyroid follicle epithelium and metastatic lymph node tissues. Histological classification was based on the General Rules for the Description of Thyroid Cancer (16). For immunohistochemical analysis, archival formalin-fixed and paraffin-embedded tissues were used. $\mathrm{h}$-prune was detected using a polyclonal antibody raised in our laboratory (15). The specificity of the anti-h-prune antibody has previously been characterized in detail (15). A Histofine SAD-PO ${ }^{\circledR}$ kit (Nichirei Biosciences, Inc., Tokyo, Japan) was used for immunohistochemical analyses. Sections were incubated with the rabbit polyclonal anti-h-prune antibody (diluted 1:100) overnight at $4^{\circ} \mathrm{C}$, then incubated with biotinylated antirabbit $\operatorname{IgG}$ and peroxidase-labeled streptavidin for $30 \mathrm{~min}$ each. In all tumors, expression of h-prune was classified as positive or negative. When $>50 \%$ of tumor cells were strongly or diffusely stained, the immunostaining was considered positive for h-prune. Written informed consent was obtained from all patients. The procedure to protect the identity of the patients was subject to approval by the institutional review committee and met the guidelines of the responsible governmental authority.

Cell lines and culture conditions. Cells of the human ATC cell line 8505C were purchased from the Riken Cell Bank (RIKEN BioResource Center, Tsukuba, Japan). KTC-3 and ACT-1 cells were kindly provided by Junichi Kurebayashi (Departments of Breast and Thyroid Surgery, Kawasaki Medical School) and Takanori Miyoshi (Department of Thoracic, Endocrine Surgery and Oncology, The University of Tokushima Graduate School), respectively (17). 8505C and KTC-3 cells were maintained in RPMI-1640 supplemented with $10 \%$ fetal bovine serum (FBS), and ACT-1 cells were maintained in Dulbecco's modified Eagle's medium (DMEM) with $10 \%$ FBS.

Inhibitors and cell transfection. Dipyridamole, a selective h-prune cAMP-PDE inhibitor and 3-isobuty-1-methylxanthine (IBMX), a non-selective cAMP-PDE inhibitor, were purchased from Sigma-Aldrich, Tokyo, Japan (18). For small interfering RNA (siRNA) analyses, the sense strand for h-prune targeting had the following sequence: 5'-GGCGUCAAGGUGGCCAU UATT-3'. Small duplex RNAs containing the same but scrambled nucleotides (siRNA SCR) were used as a negative control. siRNA transfection was performed using Lipofectamine ${ }^{\mathrm{TM}}$ RNAiMAX (Invitrogen, Carlsbad, CA, USA). Transfection with the pGL4.51 [luc/CMV/Hyglo] vector (Promega K.K., Tokyo, Japan) was performed using a jetPRIME kit (Funakoshi, Co., Ltd., Tokyo, Japan).

Western blot analysis. Protein samples obtained from the cell lysis buffer (Cell Signaling Technology Japan, Tokyo, Japan) were resolved using $10 \%$ sodium dodecyl sulfate polyacrylamide gel electrophoresis (SDS-PAGE) buffer and electrophoretically transferred onto nitrocellulose membranes. The membranes were blocked with 5\% skim milk, probed with the polyclonal anti h-prune antibody (diluted 1:2,000, raised in our laboratory), with anti-rabbit IgG antibody (ELC) at $1: 2,000$ as the secondary antibody. Blots were also probed with an anti- $\beta$ actin antibody (diluted 1:5,000; Abcam, Cambridge, UK). Amersham ECL Plus ${ }^{\mathrm{TM}}$ Western Blotting Detection system reagents (GE Healthcare Japan, Tokyo, Japan) were used for detection of antigen-antibody reactions.

Real-time reverse transcription-polymerase chain reaction (RT-PCR). Total RNA was collected from samples using RNeasy ${ }^{\circledR}$ Mini kits (Qiagen, Limburg, The Netherlands). cDNA samples were obtained from $2 \mathrm{ng}$ of total RNA with buffer, $\mathrm{Mg}$, RNase inhibitor, a random primer (6-mer), $10 \mathrm{mM}$ dNTPs, and reverse-transcriptase (SuperScript II), then amplified using an intercalation procedure with Power SYBR ${ }^{\circledR}$ Green PCR Master Mix (Life Technologies, Carlsbad, CA, USA). Results were analyzed using a relative quantitative method $(\Delta \Delta \mathrm{Ct})$.

Cell migration assay. To measure cell migration activity, Transwell and wound healing assays were performed. The Transwell migration assay was performed using a Boyden chamber $(6.5 \mathrm{~mm}$ in diameter, with $8-\mu \mathrm{m}$ pores; Costar Life Sciences, Corning, MA, USA) the bottom face of which was coated with $10 \mu \mathrm{g} / \mathrm{ml}$ fibronectin. Cells $\left(1 \times 10^{4}\right)$ suspended in serum-free medium containing $0.1 \%$ bovine serum albumin (BSA), with or without inhibitors, were applied to the upper chamber. The concentration of $0.1 \%$ dimethyl sulfoxide (DMSO) was adjusted to the same concentration as the inhibitors. After $4 \mathrm{~h}$, the number of the cells that had migrated to the lower side of the upper chamber were counted automatically using a fluorescence microscope (model BZ-9000; Keyence Corp., Osaka, Japan), and relative cell migration was expressed as the percentage of migrating cells with treatment compared to without treatment. To perform the wound-healing assay, fully confluent monolayer of cells on 24-well fibronectincoated dishes were scratched manually, and the healing rate was measured after 12 or $24 \mathrm{~h}$.

Cell invasion assay. Invasion assays were performed using $\mathrm{BD}$ BioCoat ${ }^{\mathrm{TM}}$ Matrigel Invasion chambers $(8-\mu \mathrm{m}$ pore, $\mathrm{PET}$ membrane; BD Biosciences, Franklin Lakes, NJ, USA). Cells $\left(2 \times 10^{4}\right)$ suspended in serum-free medium containing $0.1 \%$ BSA, with or without inhibitors, were applied to the upper chambers, which were inserted in 24-well plates containing $10 \%$ FBS/RPMI, with or without inhibitors. The concentrations of $0.1 \%$ DMSO were adjusted to the same concentration as the inhibitors. After 12 or $24 \mathrm{~h}$, the number of cells that had invaded the lower side of the upper chamber through the matrigel were counted automatically using a fluorescence microscope (model BZ-9000; Keyence), and relative cell invasion was expressed as the percentage of invaded cells with treatment compared to that without treatment.

Animal experiments. Six-week-old NOG/Jic (NOD/Shi-scid, IL-2R $\gamma \mathrm{KO}$ ) female mice (CLEA Japan, Inc., Tokyo, Japan) were used as models of orthotopic tumor implantation. Approximately $5 \times 10^{5}$ cells resuspended in $20 \mu \mathrm{l}$ of serumfree medium 199 were injected into the right thyroid gland of each mouse using a Hamilton syringe attached to a 27-gauge standard needle. In the dipyridamole-treated group, $0.3 \mathrm{mg} / \mathrm{kg}$ dipyridamole was administered intraperitoneally each day after cell injection. The same volume of phosphate-buffered saline (PBS) was administered to the control group in the same manner. For live imaging, 8505C-luc cells expressing the lucif- 
A

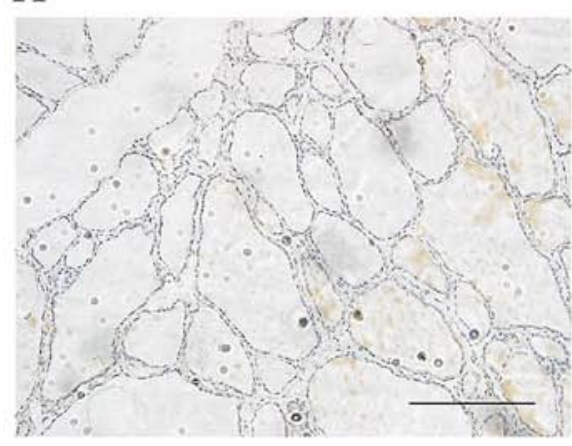

B

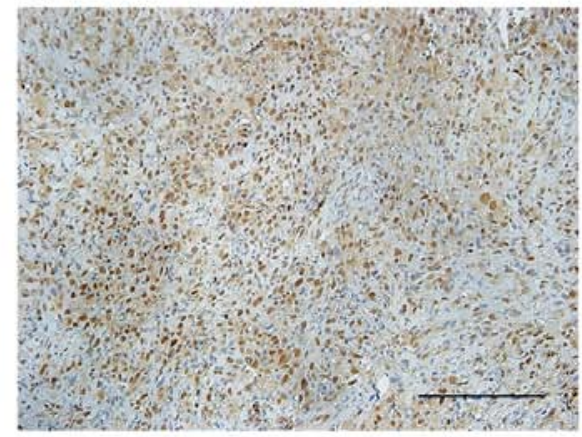

$\mathrm{C}$

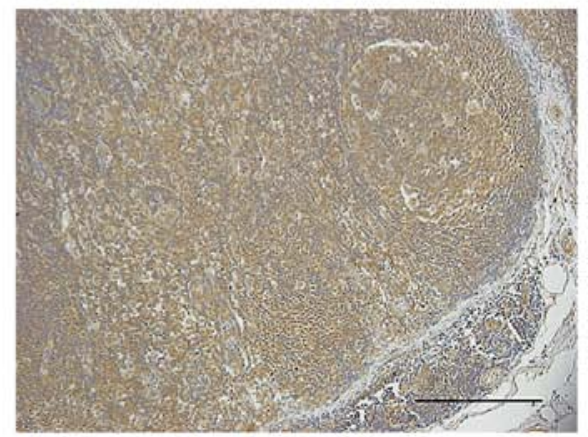

Figure 1. Immunohistochemical analysis of h-prune. (A) Non-tumor, (B) ATC and (C) lymph node metastasis of ATC. Scale bar, $200 \mu \mathrm{m}$.

Table I. Effect of inhibition of cAMP-PDE activity and h-prune expression on thyroid cancer invasion and pulmonary metastasis in an orthotopic mouse model.

\begin{tabular}{|c|c|c|c|}
\hline Characteristics & $\begin{array}{l}\text { 8505C-luc control } \\
\qquad(\mathrm{n}=3)\end{array}$ & $\begin{array}{l}\text { 8505C-luc dipyridamole } \\
\qquad(\mathrm{n}=3)\end{array}$ & P-value \\
\hline Trachea invasion & & & 0.051 \\
\hline Modest/mild & $0(0 \%)$ & $2(66.7 \%)$ & \\
\hline Moderate/severe & $3(100 \%)$ & $1(33.3 \%)$ & \\
\hline Esophagus invasion & & & 0.410 \\
\hline No & $1(33.3 \%)$ & $2(66.7 \%)$ & \\
\hline Yes & $2(66.7 \%)$ & $1(33.3 \%)$ & \\
\hline Pulmonary metastasis area for total lung field (\%) & $2.771 \pm 0.113$ & $0.645 \pm 0.066$ & $<0.001$ \\
\hline Characteristics & $\begin{array}{l}8505 C \\
(n=8)\end{array}$ & $\begin{array}{l}\text { ACT-1 } \\
(\mathrm{n}=8)\end{array}$ & P-value \\
\hline Trachea invasion & & & 0.0070 \\
\hline Modest/mild & $2(25 \%)$ & $8(100 \%)$ & \\
\hline Moderate/severe & $6(75 \%)$ & $0(0 \%)$ & \\
\hline Esophagus invasion & & & 0.0769 \\
\hline No & $4(50 \%)$ & $8(100 \%)$ & \\
\hline Yes & $4(50 \%)$ & $0(0 \%)$ & \\
\hline Pulmonary metastasis area for total lung field (\%) & $2.814 \pm 0.978$ & 0 & $<0.001$ \\
\hline
\end{tabular}

erase gene allowed measurement of bioluminescent activity as a surrogate for tumor growth. D-luciferin $(150 \mathrm{mg} / \mathrm{kg})$ was intraperitoneally administered once a week, and luciferase activity was estimated with a cooled CCD camera (NightOWL II LB 983; BMS, Tokyo, Japan). Emitted photons were measured for $180 \mathrm{sec}$. Images were analyzed using the Indigo 2 software (Berthold Technologies, Baden-Wurttemberg, Germany). All mice were necropsied on day 25 . The extent of thyroid tumor invasion was estimated using hematoxylin-eosin (H\&E) stained resected specimens. The rate of pulmonary metastasis for the lung field was obtained from average dimensions, counted automatically using a microscope (model BZ-9000; Keyence) for 5 sections cut from paraffin block of each mouse randomly. All animal studies were performed according to the guidelines set by the US National Institutes of Health (1985). This experimental protocol was approved by the ethics review committee for animal experimentation of the Graduate School of Biomedical Sciences at Hiroshima University.

Statistical analysis. Statistical analyses were conducted using JMP 11.0.0 (SAS Institute, Inc.) with the Student's t-test, the Fisher's exact probability test and the Mann-Whitney U test. P-values $<0.05$ were considered statistically significant. The data are presented as the mean \pm standard error.

\section{Results}

Expression of h-prune in anaplastic thyroid cancer tissues. In corresponding non-tumor thyroid follicle epithelium, weak focal or no staining of h-prune was observed (Fig. 1A). In contrast, all 15 ATC tissues showed diffuse staining (Fig. 1B). Furthermore, h-prune-positive cells were observed in all 8 
A
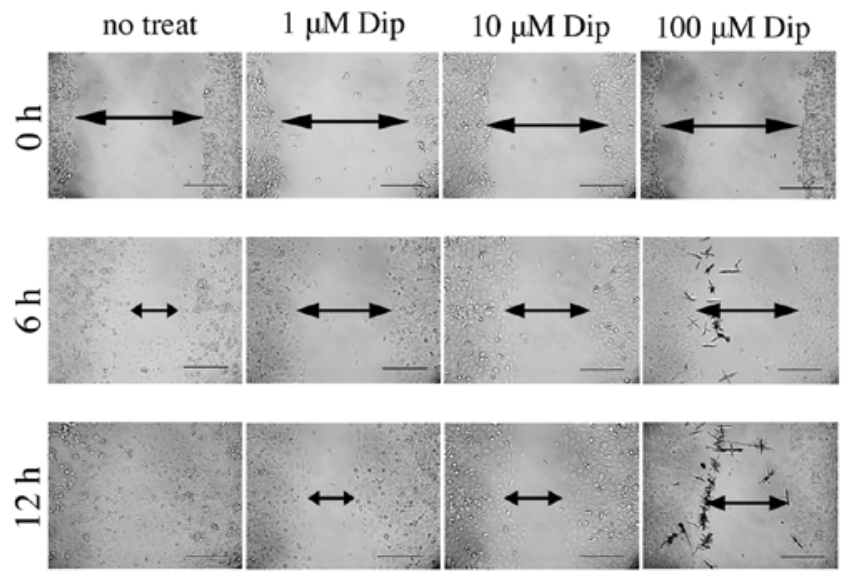

B

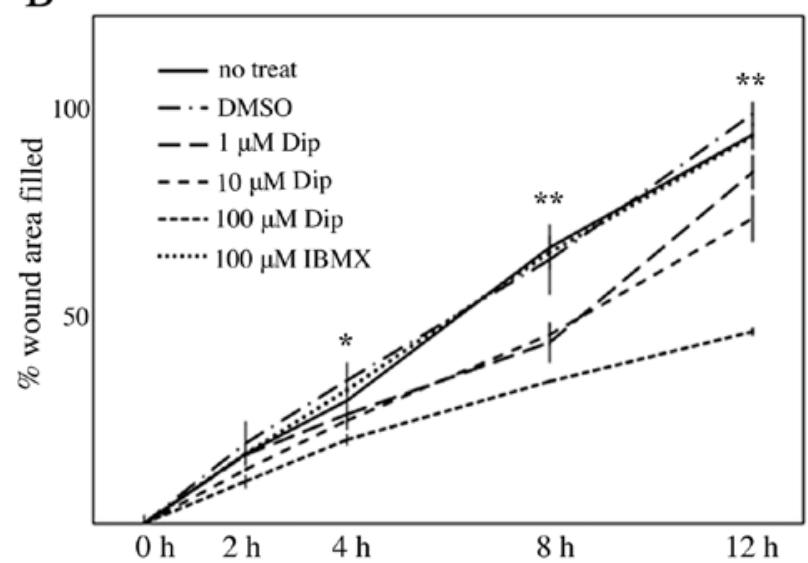

$\mathrm{F}$

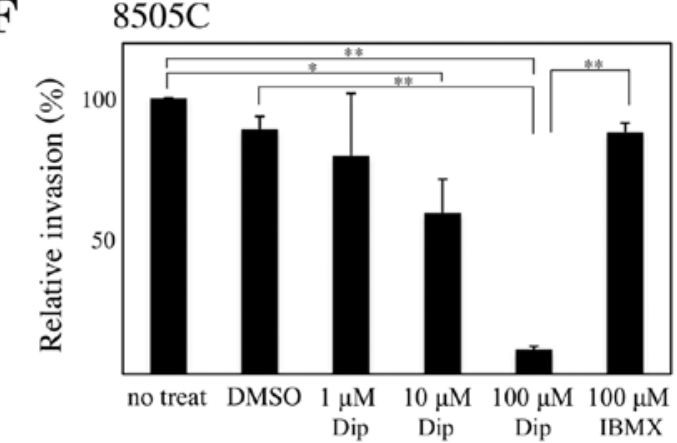

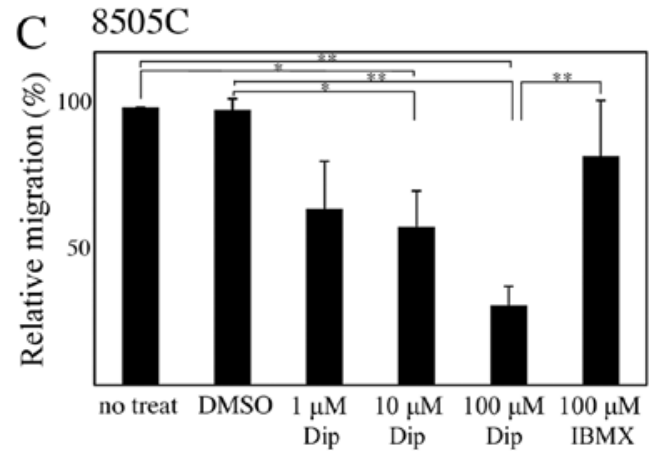

$\mathrm{D}$

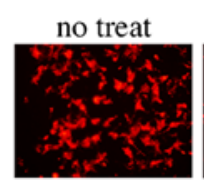

DMSO

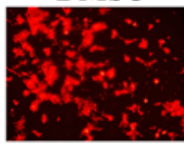

IBMX

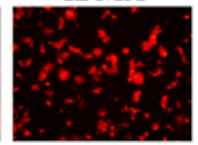

$1 \mu \mathrm{M}$ Dip

$10 \mu \mathrm{M}$ Dip

$100 \mu \mathrm{M}$ Dip
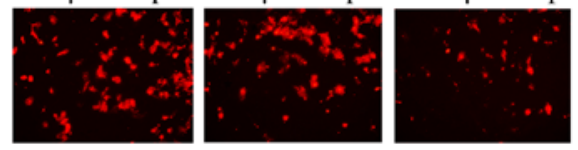

E KTC-3

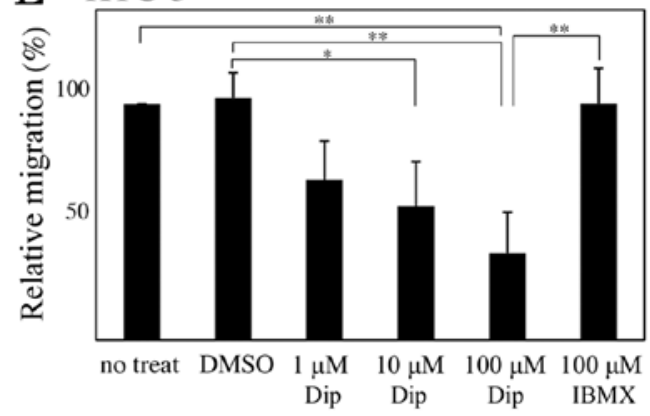

G
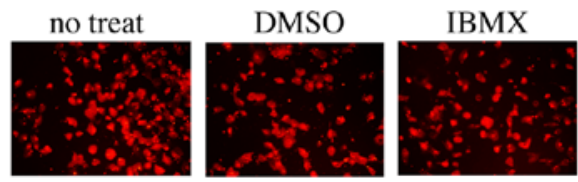

$1 \mu \mathrm{M}$ Dip

$10 \mu \mathrm{M}$ Dip

$100 \mu$ M Dip

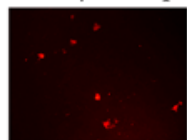

Figure 2. Involvement of cAMP-PDE activity in human ATC cell motility. (A and B) Monolayers of 8505C cells were scratched manually, and wounded cells were treated with dimethyl sulfoxide (DMSO), 1, 10 and $100 \mu \mathrm{M}$ dipyridamole (Dip), or $100 \mu \mathrm{M}$ 3-isobuty-1-methylxanthine (IBMX), and allowed to heal for $12 \mathrm{~h}$. Wound-healing rates were measured at 2, 4, 8 and $12 \mathrm{~h}$. The width of wounds are indicated with arrows. (C-E) 8505C (C and D) and KTC-3 (E) cells treated with DMSO, 1, 10 and $100 \mu \mathrm{M}$ Dip, and $100 \mu \mathrm{M}$ IBMX were subjected to a Transwell cell migration assay. (F and $\mathrm{G}$ ) $8505 \mathrm{C}$ cells were subjected to a Transwell cell invasion assay. The results are shown as a ratio compared with no treatment (no treat), as means \pm SE. Error bars indicate the SE. " $\mathrm{P}<0.05$, ${ }^{* * *} \mathrm{P}<0.01$.

corresponding ATC lymph node metastasis tissue samples (Fig. 1C).

Involvement of h-prune PDE activity in ATC cell motility. To investigate whether the cAMP-PDE activity of h-prune is necessary for ATC cell motility, 8505C and KTC-3 cells treated with DMSO, dipyridamole, and IBMX were subjected to Transwell migration and wound healing assays. In the wound healing assay, dipyridamole suppressed $8505 \mathrm{C}$ cell migration in a concentration-dependent manner (Fig. 2A and B). Dipyridamole also suppressed $8505 \mathrm{C}$ and KTC-3 cell migration in a concentration-dependent manner in the Transwell migration assay (Fig. 2C-E). Furthermore, 8505C cells treated with dipyridamole showed concentration-dependent reduced cell invasion (Fig. 2F and G).

Involvement of h-prune expression in ATC cell motility. To investigate whether h-prune protein expression is necessary for ATC cell motility, we depleted endogenous h-prune in $8505 \mathrm{C}$ and KTC-3 cells by RNA interference. Treatment 
A

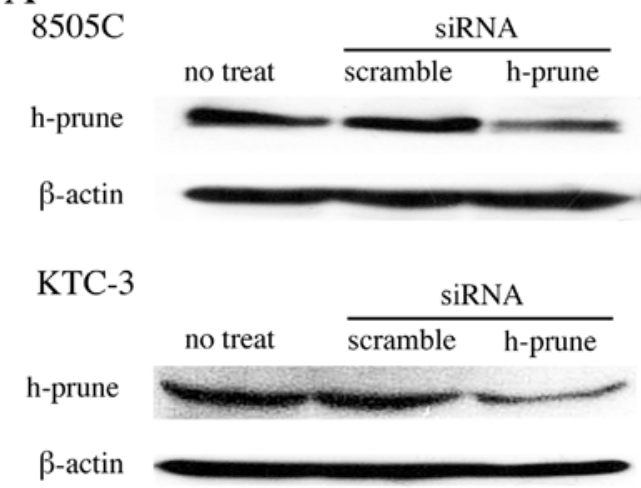

C

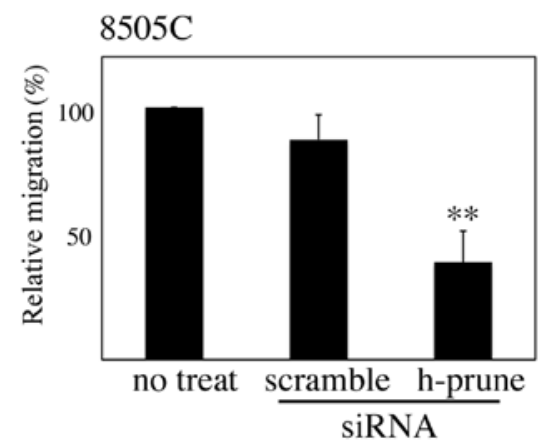

E

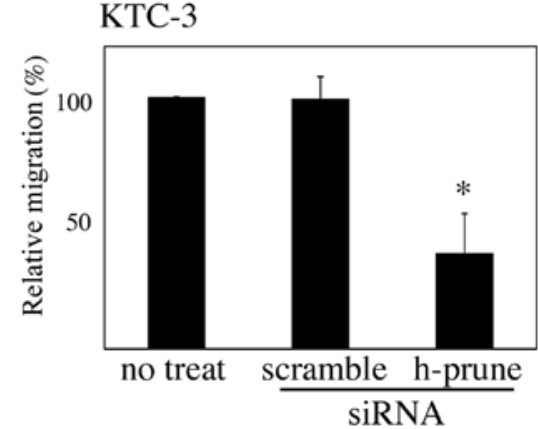

B

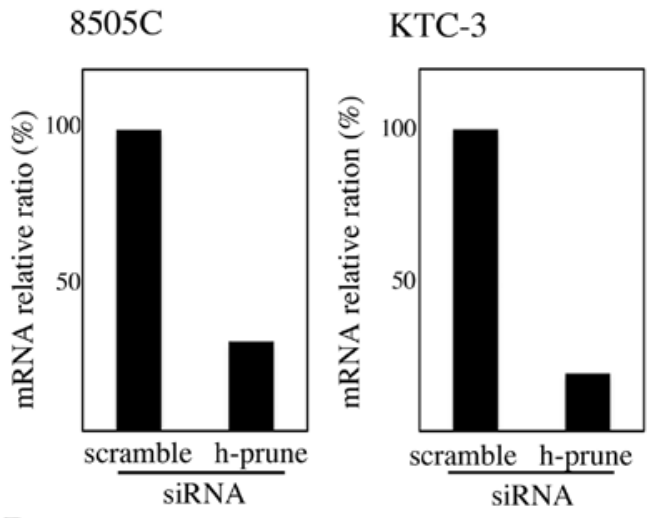

D

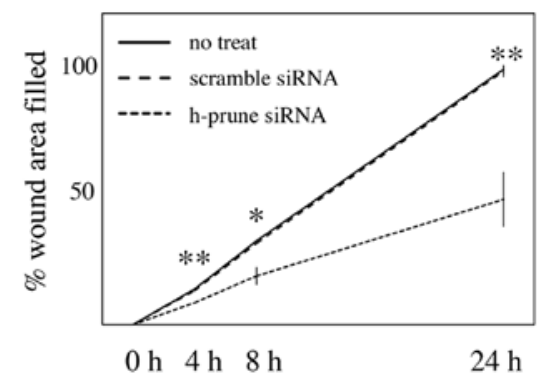

F

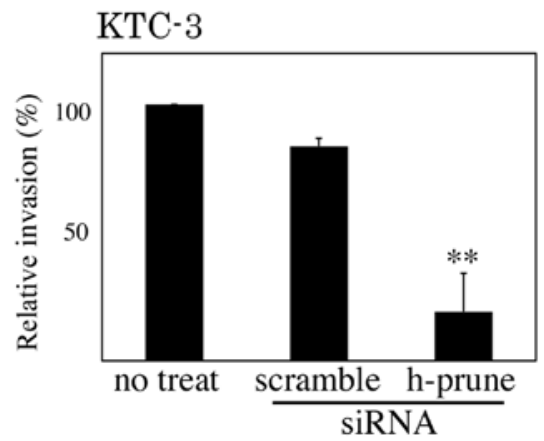

Figure 3. Involvement of h-prune expression in human ATC cell motility. (A) Lysates of 8505C and KTC-3 cells transfected with scrambled siRNA and siRNA for h-prune were evaluated by western blot analysis using a polyclonal h-prune antibody. (B) Relative ratio of h-prune mRNA in $8505 \mathrm{C}$ and KTC-3 cells transfected with scrambled siRNA and siRNA for h-prune detected with quantitative PCR. (C) 8505C cells transfected with scrambled siRNA and siRNA for h-prune were subjected to a Transwell cell migration assay. (D) KTC-3 cells transfected with scrambled siRNA and siRNA for h-prune were subjected to a Transwell cell migration assay. (E) Monolayers of confluent 8505C cells transfected with scrambled siRNA and siRNA for h-prune were scratched manually, and the wound-healing rate was measured for $24 \mathrm{~h}$. (F) KTC-3 cells transfected with scrambled siRNA and siRNA for h-prune were subjected to a Transwell cell invasion assay. The results are shown as means \pm SE. Error bars indicate the $\mathrm{SE} .{ }^{*} \mathrm{P}<0.05,{ }^{* *} \mathrm{P}<0.01$.

with siRNA for h-prune reduced the protein levels but not levels of $\beta$-actin (Fig. 3A). Quantitative RT-PCR showed that expression of $h$-prune mRNA was also reduced by treatment with siRNA for h-prune (Fig. 3B). The Transwell migration assay revealed that the reduction of h-prune by RNAi in 8505C and KTC-3 cells resulted in reduced cell migration (Fig. 3C and D), and the wound healing assay revealed that the reduction of h-prune by RNAi in $8505 \mathrm{C}$ cells resulted in reduced cell migration (Fig. $3 \mathrm{E}$ ). We also found that reduction of h-prune by RNAi in KTC-3 cells resulted in reduced cell invasion (Fig. 3F).

The effect of inhibition of h-prune PDE activity on thyroid tumor growth, invasion, and pulmonary metastasis in an orthotopic mouse model. To clarify the ability of dipyridamole to inhibit tumor invasion and pulmonary metastasis in vivo, we generated 8505C-luc orthotopic xenografts in mice. Luciferase activity and representative images of orthotopic tumors at the time of necropsy showed enlargement of tumor around the trachea and surrounding tissue in mice administered PBS as control while dipyridamole-treated mice showed a significantly suppressed tumor growth as measured by bioluminescence activity at day $25(\mathrm{P}<0.05$; Fig. $4 \mathrm{~A}$ and $\mathrm{B})$ and suppressed invasion into the trachea and the surrounding tissue (Fig. 4C). In pathological analysis, while trachea invasion with breaking tracheal mucosa and cartilages and multiple pulmonary metastasis were found in control mice, dipyridamole-treated mice showed significantly suppressed trachea invasion and pulmonary metastasis (Fig. 4D and E; Table I).

The effect of h-prune expression on thyroid tumor growth, invasion and pulmonary metastasis in an orthotopic mouse model. 
A
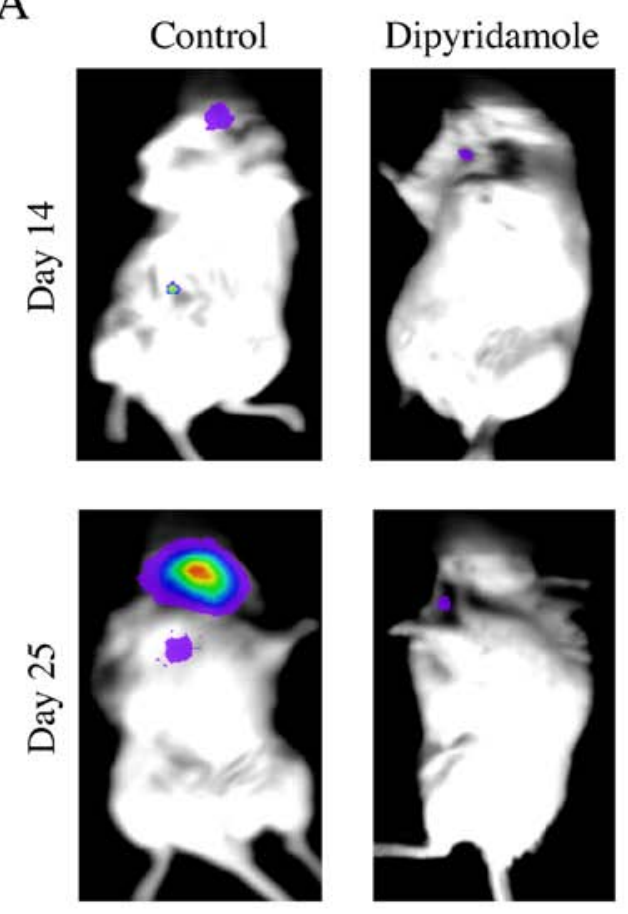

$\mathrm{D}$

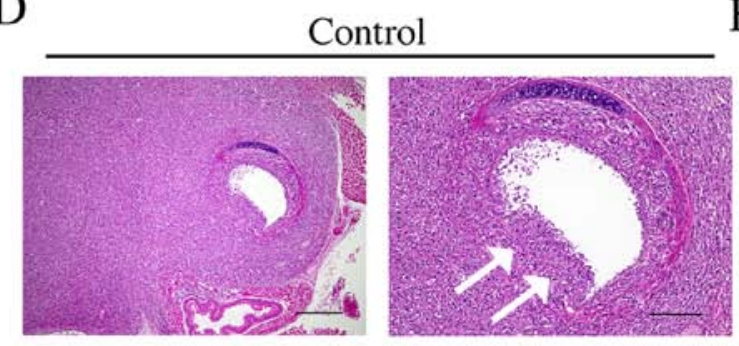

Dipyridamole
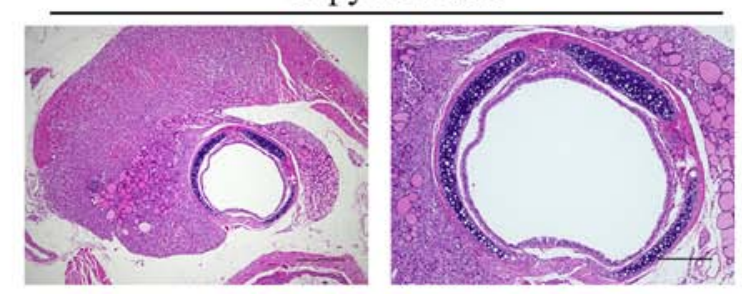

$\mathrm{B}$

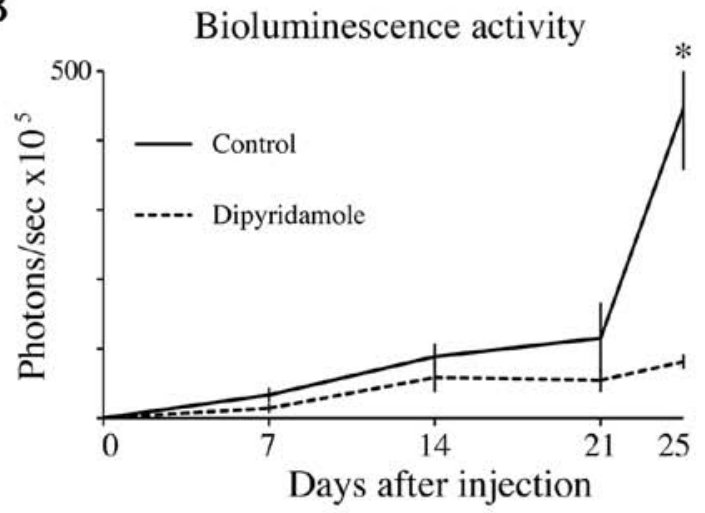

C
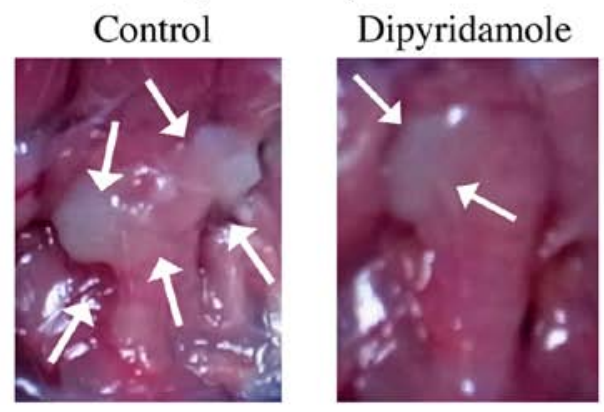

$\mathrm{E}$

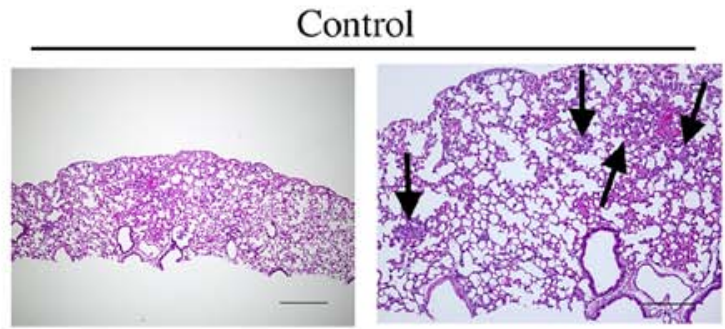

Dipyridamole

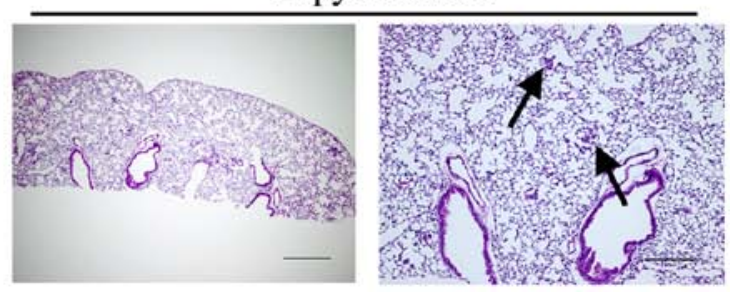

Figure 4. Inhibition of cAMP-PDE activity suppresses thyroid tumor growth, invasion and pulmonary metastasis in an orthotopic mouse model. 8505Cluc cells were injected to the right thyroid gland of NOD mice and $0.3 \mathrm{mg} / \mathrm{kg}$ dipyridamole or control PBS was administered intraperitoneally each day. (A) Luciferase activity in control (left) and dipyridamole-treated (right) mice on day 14 and day 25. (B) Luciferase activity was measured as photons/sec in control and dipyridamole-treated mice. (C) Orthotopic tumors in control (left panel) and dipyridamole-treated (right panel) mice at the time of necropsy on day 25. Tumors are indicated with white arrows. (D and E) Pathological analysis of thyroid tumors invading to trachea (white arrows) and pulmonary metastases (black arrows) in control (upper panel) and dipyridamole-treated (lower panel) mice treated with H\&E stain (left: scale bar, $0.5 \mu$ m; right: scale bar, $0.2 \mu \mathrm{m}$ ). The results are shown as means $\pm \mathrm{SE}$. Error bars indicate the $\mathrm{SE}$. ${ }^{*} \mathrm{P}<0.05$.

ACT-1 cells exhibited lower h-prune expression than $8505 \mathrm{C}$ cells (Fig. 5A) and the cell migration assay revealed that ACT-1 cells showed impaired cell migration ability compared to $8505 \mathrm{C}$ cells $(\mathrm{P}<0.05$; Fig. $5 \mathrm{~B})$. Thus, we tested whether h-prune protein expression levels affect tumor growth, invasion, and pulmonary metastasis in vivo, by using $8505 \mathrm{C}$ an ACT-1 murine orthotopic xenograft model. The $8505 \mathrm{C}$ mice had larger tumors that involved the trachea and surrounding tissue than the ACT-1 mice (Fig. 5C). In the pathological analysis, more severe tracheal and esophageal invasion and more frequent pulmonary metastasis were observed in the 8505C mice than in the ACT-1 mice (Fig. 5D and E; Table I).

\section{Discussion}

Previous reports have shown that in several types of cancer, h-prune overexpression is correlated with advanced tumor stage and poor prognosis. Forus et al (18) reported amplification of the PRUNE gene in aggressive sarcoma subtypes. Zollo et al (12) reported that overexpression of h-prune in breast cancer patients was correlated with advanced lymph node status and the presence of distant metastases. We previously showed that h-prune protein expression was correlated with depth of invasion and degree of lymph node metastasis in colorectal and pancreatic cancers (15). Patients with h-prune- 
A

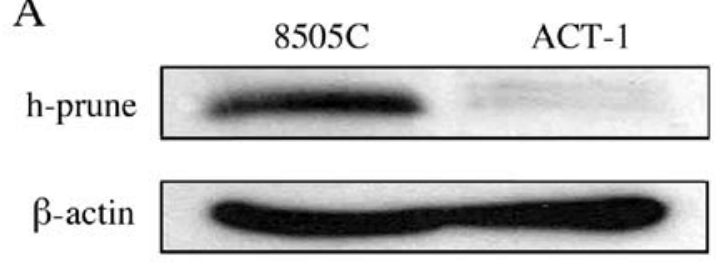

B

C

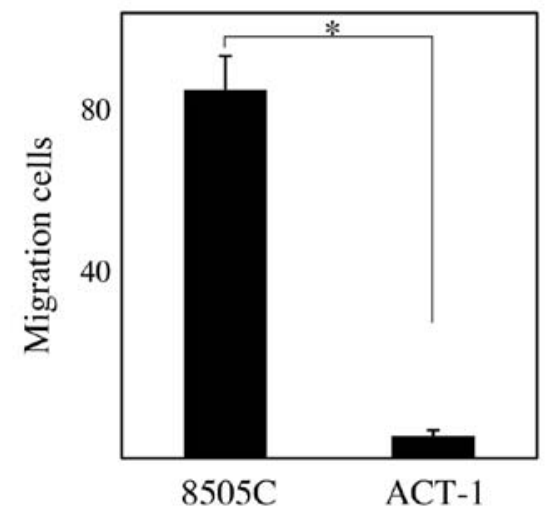

$8505 \mathrm{C}$

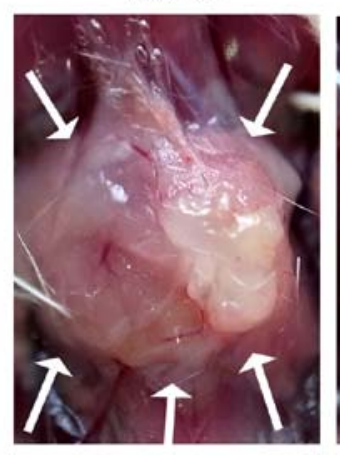

ACT-1

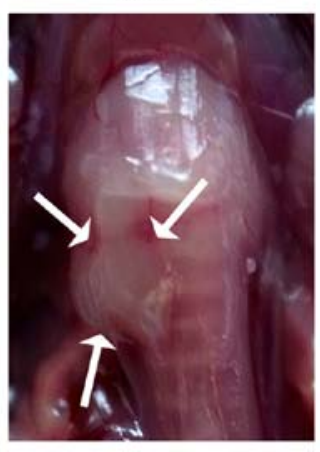

D

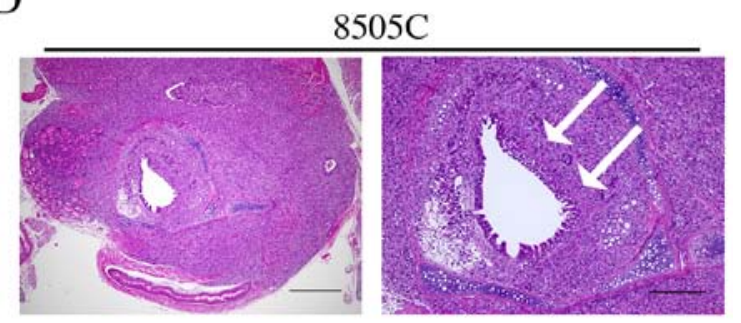

ACT-1

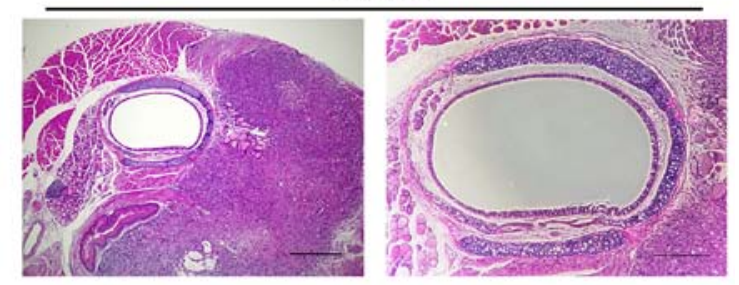

E
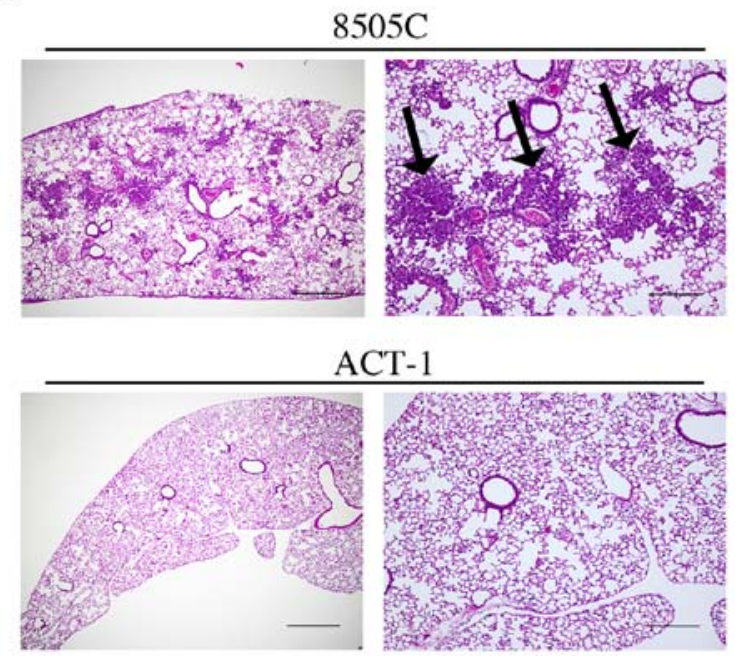

Figure 5. Decreased expression of h-prune suppresses thyroid tumor growth, invasion and pulmonary metastasis in an orthotopic mouse model. 8505C or ATC-1 cells were injected into the right thyroid gland of NOD mice. (A) Expression of protein levels of h-prune in cell lines derived from human ATC cells, 8505C and ACT-1 were evaluated by western blot analysis using a polyclonal h-prune antibody. (B) 8505C and ACT-1 cells were subjected to a Transwell cell migration assay. (C) Orthotopic tumors of $8505 \mathrm{C}$ (left panel) and ACT-1 (right panel) mice at the time of necropsy on day 25 . Tumors are indicated with white arrows. (D and E) Pathological analysis of thyroid tumors invading to trachea (white arrows) and pulmonary metastases (black arrows) in 8505C (upper panel) and ACT-1 (lower panel) mice treated with H\&E stain (left: scale bar, $0.5 \mu \mathrm{m}$; right: scale bar, $0.2 \mu \mathrm{m}$ ). The results are shown as means \pm SE. Error bars indicate the SE. ${ }^{*} \mathrm{P}<0.001$.

positive gastric cancer had a significantly worse survival rate than patients with h-prune-negative gastric cancer (13). In addition, in esophageal squamous cell carcinoma patients, h-prune-positive staining was significantly correlated with tumor stage and independent predictors of survival (14). These results suggest that h-prune can be used as a marker for the identification of subsets of cancer patients with highly aggressive tumors. In the present study, although h-prune is not appropriate as a marker for the identification of highly aggressive subsets of thyroid cancer patients, h-prune was frequently expressed in ATC tissues and corresponding lymph node metastasis.

Present study showed that inhibition of both expression and PDE activity of h-prune downregulated thyroid cancer cell migration and invasion in vitro, consistent with previous reports $(15,19)$. Although the molecular mechanisms by which h-prune regulates cell motility remain to be suffi- ciently defined, previous reports have suggested that h-prune might regulate cell motility by two different means of action: through its PDE activity and its interactions with protein partners.

One mechanism by which h-prune stimulates cell motility and metastasis is through its PDE activity, which can be suppressed by dipyridamole, a pyrimido[5,4-d]pyrimidine analogue (19). H-prune has been reported to possess cAMPPDE activity, with a preferential affinity for cAMP over cGMP as a substrate, with $\mathrm{Km}$ values of $0.9 \pm 0.03$ and $2.3 \pm 0.11 \mathrm{M}$, respectively (19). Dypiridamole has been used as an antiplatelet-aggregation agent, and its activity as a selective PDE inhibitor has been tested in various studies. Inhibition of PDE activity with dipyridamole suppressed cell motility, indicating that h-prune PDE activity might be critical for cellular motility (19). In the present study, dipyridamole suppressed ATC cell motility and invasiveness in vitro, and 
also suppressed cancer invasiveness and lung metastasis in an orthotopic mouse model. These results suggested that the PDE activity of h-prune might be necessary for cancer invasion and metastasis.

In the present study, h-prune protein expression levels were involved in migration and invasion of ATC cell lines, and metastasis in murine orthotopic xenograft model. H-prune has been reported to interact with several proteins, including nm23-H1, GSK-3 and ASAP1 (15,20-22). These proteins have been reported to act as a regulator of cancer metastasis $(20,23)$. Thus, h-prune may promote anaplastic cancer cell motility through an interaction with several protein partners.

A limitation of the present study is that immunohistochemistry showed that h-prune was frequently expressed in all ATC tissues. According to this result, h-prune may not be correlated with aggressiveness. Thus, the inhibition of h-prune function may critically affect the maintenance of the cancer cell itself. However, the MTT assay showed that dipyridamole had no significant effect on cell proliferation (data not shown).

In conclusion, h-prune is frequently expressed in ATC cells and lymph node metastasis, and promotes migration and invasion of ATC cells and metastasis in an anaplastic thyroid cancer model. Thus, h-prune shows promise as a targeting candidate against ATC.

\section{Acknowledgements}

We are grateful to Junichi Kurebayashi and Takanori Miyoshi, for donating cells. We thank the Analysis Center of Life Science, Hiroshima University for the use of their facilities.

\section{References}

1. Ain KB: Anaplastic thyroid carcinoma: A therapeutic challenge. Semin Surg Oncol 16: 64-69, 1999.

2. Demeter JG, De Jong SA, Lawrence AM and Paloyan E: Anaplastic thyroid carcinoma: risk factors and outcome. Surgery 110: 956-961, 1991.

3. Hundahl SA, Fleming ID, Fremgen AM and Menck HR: A National Cancer Data Base report on 53,856 cases of thyroid carcinoma treated in the U.S., 1985-1995 [see commetns]. Cancer 83: 2638-2648, 1998.

4. Kebebew E, Greenspan FS, Clark OH, Woeber KA and McMillan A: Anaplastic thyroid carcinoma. Treatment outcome and prognostic factors. Cancer 103: 1330-1335, 2005.

5. Nel CJ, van Heerden JA, Goellner JR, Gharib H, McConahey WM, Taylor WF and Grant CS: Anaplastic carcinoma of the thyroid: A clinicopathologic study of 82 cases. Mayo Clin Proc 60: 51-58, 1985.

6. Tan RK, Finley RK III, Driscoll D, Bakamjian V, Hicks WL Jr and Shedd DP: Anaplastic carcinoma of the thyroid: A 24-year experience. Head Neck 17: 41-47, discussion 47-48, 1995.
7. Venkatesh YS, Ordonez NG, Schultz PN, Hickey RC, Goepfert H and Samaan NA: Anaplastic carcinoma of the thyroid. A clinicopathologic study of 121 cases. Cancer 66: 321-330, 1990.

8. Voutilainen PE, Multanen M, Haapiainen RK, Leppäniemi AK and Sivula AH: Anaplastic thyroid carcinoma survival. World J Surg 23: 975-978, discussion 978-979, 1999.

9. Shaha AR: Implications of prognostic factors and risk groups in the management of differentiated thyroid cancer. Laryngoscope 114: 393-402, 2004

10. Nagaiah G, Hossain A, Mooney CJ, Parmentier J and Remick SC: Anaplastic thyroid cancer: A review of epidemiology, pathogenesis, and treatment. J Oncol 2011: 542358, 2011.

11. Marino N and Zollo M: Understanding h-prune biology in the fight against cancer. Clin Exp Metastasis 24: 637-645, 2007.

12. Zollo M, Andrè A, Cossu A, Sini MC, D'Angelo A, Marino N, Budroni M, Tanda F, Arrigoni G and Palmieri G: Overexpression of h-prune in breast cancer is correlated with advanced disease status. Clin Cancer Res 11: 199-205, 2005.

13. Oue N, Yoshida K, Noguchi T, Sentani K, Kikuchi A and Yasui W: Increased expression of h-prune is associated with tumor progression and poor survival in gastric cancer. Cancer Sci 98: 1198-1205, 2007.

14. Noguchi T, Oue N, Wada S, Sentani K, Sakamoto N, Kikuchi A and Yasui W: h-Prune is an independent prognostic marker for survival in esophageal squamous cell carcinoma. Ann Surg Oncol 16: 1390-1396, 2009.

15. Kobayashi T, Hino S, Oue N, Asahara T, Zollo M, Yasui W and Kikuchi A: Glycogen synthase kinase 3 and h-prune regulate cell migration by modulating focal adhesions. Mol Cell Biol 26: 898-911, 2006.

16. The Japanese Society of Thyroid Surgery. General Rules for the Description of Thyroid Cancer. 6th edition. Kanehara Press, Tokyo, Japan, 2005.

17. Kurebayashi J, Okubo S, Yamamoto Y, Ikeda M, Tanaka K, Otsuki T and Sonoo H: Additive antitumor effects of gefitinib and imatinib on anaplastic thyroid cancer cells. Cancer Chemother Pharmacol 58: 460-470, 2006.

18. Forus A, D'Angelo A, Henriksen J, Merla G, Maelandsmo GM, Flørenes VA, Olivieri S, Bjerkehagen B, Meza-Zepeda LA, del Vecchio Blanco F, et al: Amplification and overexpression of PRUNE in human sarcomas and breast carcinomas - a possible mechanism for altering the $\mathrm{nm} 23-\mathrm{H} 1$ activity. Oncogene 20: 6881-6890, 2001

19. D'Angelo A, Garzia L, André A, Carotenuto P, Aglio V, Guardiola O, Arrigoni G, Cossu A, Palmieri G, Aravind L, et al: Prune cAMP phosphodiesterase binds nm23-H1 and promotes cancer metastasis. Cancer Cell 5: 137-149, 2004.

20. Steeg PS: Metastasis suppressors alter the signal transduction of cancer cells. Nat Rev Cancer 3: 55-63, 2003.

21. Carotenuto M, De Antonellis P, Liguori L, Benvenuto G, Magliulo D, Alonzi A, Turino C, Attanasio C, Damiani V, Bello AM, et al: H-Prune through GSK-3 $\beta$ interaction sustains canonical WNT/ $\beta$-catenin signaling enhancing cancer progression in NSCLC. Oncotarget 5: 5736-5749, 2014.

22. Müller T, Stein U, Poletti A, Garzia L, Rothley M, Plaumann D, Thiele W, Bauer M, Galasso A, Schlag P, et al: ASAP1 promotes tumor cell motility and invasiveness, stimulates metastasis formation in vivo, and correlates with poor survival in colorectal cancer patients. Oncogene 29: 2393-2403, 2010.

23. Lin D, Watahiki A, Bayani J, Zhang F, Liu L, Ling V, Sadar MD, English J, Fazli L, So A, et al: ASAP1, a gene at 8q24, is associated with prostate cancer metastasis. Cancer Res 68: 4352-4359, 2008. 